Article

\title{
Research Contribution of the Oldest Seat of Higher Learning in Pakistan: A Bibliometric Analysis of University of the Punjab
}

\author{
Shakil Ahmad ${ }^{1}$, , Yasir Javed ${ }^{1, *(\mathbb{D})}$, Shabir Hussain Khahro ${ }^{1 \mathbb{C}}$ and Arslan Shahid ${ }^{2}$ \\ 1 Prince Sultan University, 11586 Riyadh, Saudi Arabia; shakil@psu.edu.sa (S.A.); \\ shkhahro@psu.edu.sa (S.H.K.) \\ 2 University of Engineering and Technology, Taxila, Rawalpindi, Punjab, Pakistan; arslan447s@gmail.com \\ * Correspondence: yjaved@psu.edu.sa
}

Received: 5 July 2020; Accepted: 1 September 2020; Published: 8 September 2020

\begin{abstract}
Bibliometric methods are used to access various elements in any data set. Similarly, this study uses a bibliometric method to evaluate the research performance of the University of the Punjab (PU), the oldest university of Pakistan. A peer university from a neighboring country, India, has been selected in this study along with three state-owned universities of Pakistan. The research yield of selected universities was analyzed since their establishment until 2019. The data were retrieved from the Scopus database in February 2020. The guidelines of the Carnegie Classification of Institutions of Higher Education were used to select the peer universities. It has been analyzed that steady progress in research productivity was observed during the 20th century and in the last few years of the 19th century. A focus shift was observed with the onset of the 21st century and a rapid increase in research publications was observed in Pakistani universities. Around $92 \%$ of research studies of the University of the Punjab were carried out during the first 20 years of the 21st century and it leads the compared peer universities in terms of the number of research publications and the citations. It is also analyzed that there is a tendency among the authors of studied universities to publish their research articles in subscription-based journals. The authors affiliated with the University of the Punjab are more inclined to publish their research in open access journals as compared to the researchers of other studied universities. It is also observed that publications with single authors received a low average of citations per document while the publications with six or more authors had the highest average citations. The study recommends collaborative efforts for carrying out research and publication in open access journals is encouraged because of greater visibility, access, and impact.
\end{abstract}

Keywords: University of the Punjab; Punjab University (PU); research performance; research output; bibliometrics; research audit; research productivity

\section{Introduction and Historical Background}

This paper presents the current state of published research of University of the Punjab, Lahore, Pakistan. Bibliometric method of research analysis is used to prepare this study. A comparison of research productivity of the University of the Punjab is made with similar universities in three other provinces of the country. A peer university established in the same period by the same British rulers of undivided India is also selected to compare with. Guidelines set by the Carnegie Classification of Institutions of Higher Education [1] are used to select the peer universities for comparison.

South Asia is heir to ancient traditions of formal and informal learning. These learning traditions varied from region to region and different socioeconomic classes [2]. Foreign travelers used to travel to India in pursuance of learning because India was considered as a seat of learning. An indigenous 
system of education was in place in India until the British introduced the western system of education in the 19th century in most parts of undivided India. This indigenous education system that was prevalent in India for centuries influenced shaping the British education policy in India [3]. The indigenous schools were owned and run by native Hindus, Sikhs, and Muslims for their respective communities on self-help bases. In the Punjab part of India, a decline in educational activities and student enrolments was observed by some researchers during the British Era. According to Leitner [4], an officer in British India, there was a decrease in the number of students attending schools during the British rule in Punjab province. Around 300,000 students were enrolled in indigenous schools before the annexation of Punjab province in 1849. This number decreased in later years during the British rule in the area.

The aims of establishing the western education system for India were to train the Indians to provide support in the administration of the country, raising the moral standard and developing economic resources of the country [5]. The universities were set up to educate the second-tier bureaucracy. For colonial masters, it was not feasible to bring all the officers and educated workers from England [6]. Universities lacked financial resources to conduct quality research and attract the best minds. At the time of British India partition in 1947, the established educational resources and institutions allocated to Pakistan were fewer compared to India. Pakistan inherited a weak foundation of primary and higher education. The problem was aggravated further with the migration of experienced Hindu, Sikh, British teachers and administrative staff. It was difficult for comparatively less educated Muslims to fill the gap created by the migration of skilled and experienced workers. The University of the Punjab was the only established university at that time. The other available university, University of Sindh, received its charter in 1947 and was not fully established at the time of partition [7].

The University of the Punjab, established in 1882, is the oldest and the largest institution of higher education in Pakistan [8]. The university comprises five campuses in Punjab province, thirteen deanships, ten constituent colleges, seventy-three centers, institutions and departments, 867 regular faculty members, 615 affiliated colleges, 44,660 on-campus students and 545,009 students in affiliated colleges, including private registered students [9]. It is significant to know the research standing of the premier institute of higher education in the country. With this inquiring approach, this study is conducted to answer the following research questions:

- What is the university's research output in terms of research publications during its 137 years' life?

- What is the impact of this research in terms of citations in PU publications by other researchers?

- What are the frequently publishing subject areas of PU researchers?

- Which are the preferred journals PU researchers prefer to publish their research?

- How different is the impact of research on open access and subscription-based journals?

- What is the relative research position of PU in similar/peer universities?

\section{Literature Review}

Universities' core business is teaching and research. The worth of an institution is determined by the quantity and quality of research associated with the institution [10]. The research contribution of faculty and researchers affiliated with academic institutions is considered as an indicator to estimate the research output. Therefore, it is necessary to account for the quantity and quality of the research output of the universities [11]. It is the quality of the research that distinguishes the institutions from their peers and competitors. Institutions producing good quality research also attract the attention of funding agencies and, consequently, receive the significant share of public funding [12]. Likewise, governments need to estimate the research performance of institutions to analyze the outcomes of their research funding. By identifying low and high productivity institutions, the government could achieve its objective of maximizing the added value of low productive institutions [13]. One of the methods used for such assessment is the bibliometric analysis of research output, such as quantifying the number of publications and the share of citations received on these publications [14]. 
The literature reveals that several bibliometric studies have been conducted to evaluate research output in particular subject areas [15-19]. Some other studies are carried out to perform bibliometric analysis on particular journals [20-24]. Further studies are conducted to evaluate the research output of institutions [25-28].

Bio-bibliometrics are used to examine the research productivity of researchers [29,30]. Some researchers have focused on evaluating the research performance of countries and regions [31-33]. Some bibliometric studies also cover humanitarian issues [34,35]. Various bibliometric studies, e.g., [36-40], have also been conducted in Pakistan. Limited attempts have been made to focus on measuring the research performance of universities, i.e., [41]. However, as per the authors' best knowledge and literature reviewed, none of the research has been conducted to measure the research performance of the University of the Punjab using the bibliometric method. Therefore, this paper provides empirical evidence for decision making in incentivizing research and allocating funds.

Research productivity by Pakistani universities has been slow in the first 50 years of independence, but it gained momentum in the last two decades due to the country's growth in Information Communication Technology (ICTs) and universities' vision for better local, regional and international rankings. [42] A study was carried out to observe the impact of ICT on research and development at the University of the Punjab. The research concluded that research grants, research incentives, and travel grants resulted in significant growth in the research output of the university in Pakistan. It is also observed that the subscription to electronic databases by Higher Education Commission on consortium bases for its National Digital Library project, Pakistan Research Repository, and other initiatives have contributed positively to influencing the research landscape of higher education institutions in Pakistan [43].

\section{Methods}

The data for this research have been extracted from the Scopus database. Scopus is one of the largest indexing databases of peer-reviewed literature [44,45]. The data were retrieved in February 2020. The research publications of selected universities were retrieved from Scopus until 31 December 2019. The year 2020 was excluded from the search criteria for not representing the entire year. The guidelines of the Carnegie Classification of Institutions of Higher Education were used to select the peer universities to know PU's research standing among peer universities. Additionally, the following criteria were used to select peer universities:

- The selected university should be from the "public" sector.

- The selected university should be registered in the "general" category of subjects and fields.

- The selected university should be situated in other provinces/states of the country.

- The selected university should be governed by a similar provincial/state administration and has similar funding sources.

- The non-Pakistani university selected for comparison must have been established in the same period by the same British rulers as the University of Punjab.

Four universities, three from Pakistan, and one from India, met the criteria and were selected for comparison. The data contained publication records of PU and all selected peer universities including:

- University of Karachi (KU)

- University of Baluchistan (BU)

- University of Peshawar (UP)

- University of Allahabad (AU)

\section{Limitations:}

1. Data for this study are limited to the Scopus database only.

2. Actual citation count is extracted from Scopus. 
3. Although the Scopus claims to be one of the largest databases of peer-reviewed literature, however, it does not index all the published resources due to its indexing policy. Therefore, the study may have missed the documents that are not indexed in Scopus. The comparatively low indexing coverage of books database can be the limitation.

4. A portion of research in Pakistan is published in Urdu, the national language of the country. The scholarly literature published in Urdu and other regional languages is not covered.

5. Various researchers have argued against the citation count method for research evaluation. A document has been cited highlighting drawbacks in that particular study. Hence, citations cannot be presumed as the indicator of the quality solely and in all the cases. For this, the adopted citation analysis method is not failsafe. Furthermore, the raw citation counts might be misleading due to differences in field and time, whereas normalized citation scores often yield a better proxy for the paper quality.

\section{Data Analysis}

The analysis of this paper is divided into two major parts: Quantitative and Qualitative The quantitative part contains detailed analysis on:

- The volume and growth of the research publications

- $\quad$ Research place of PU in the studied universities

- Researchers' access preference and document types of publishing their research

- $\quad$ Subject strengths of the universities concerning research output

- The qualitative part contains detailed analysis on:

- Measuring research impact through citations analysis

- Collaboration patterns assessment of the research output

- Nobel laureates produced by the peer universities

- $\quad$ Research Output and Share of PU

- A sharp increase is observed in the research output of PU and other Pakistani universities at the beginning of the 21st century. In PU's 137 historical years, around 92\% of its total publications are in the first 20 years of this century. The case is almost similar to other peer universities of Pakistan. On average, $89 \%$ of the total publications of compared Pakistani universities are published in the past 20 years. The case of AU, the other peer university form India is slightly different, with $60 \%$ of its publications published in the 21st century. The growth in the research productivity of PU and other Pakistani universities in 21st century could be attributed to the availability of ICT, the establishment of HEC in 2002 and universities' vision for the better regional, national and international rankings as indicated by [42]. Indeed, HEC marked a phenomenal impact in the higher education and research output of Pakistani Universities. Figure 1 shows the year wise productivity of PU and peer universities. The figures represent publication data from the year 1974 till 2019.

- The slow progress in research is observed during the British period and in the early decades after the independence for PU and AU. Researchers are critical to the system of education based on which these universities were established by the British rulers. Universities lacked financial resources to conduct quality research and attract the best minds. The universities were mainly focusing on teaching activities rather than research [46]. Howell [47] stated the condition of education in India during the British rule, "Education in India under the British government was first ignored, then violently and successfully opposed, then conducted on a system now universally admitted to be erroneous and finally placed on its present footing". Retaining these characteristics by Pakistani universities resulted in the lack of quality research [48]. This culture impacted the universities even after the British left the sub-continent. The University of the Punjab was not an exception, and it inherited weak research culture. 

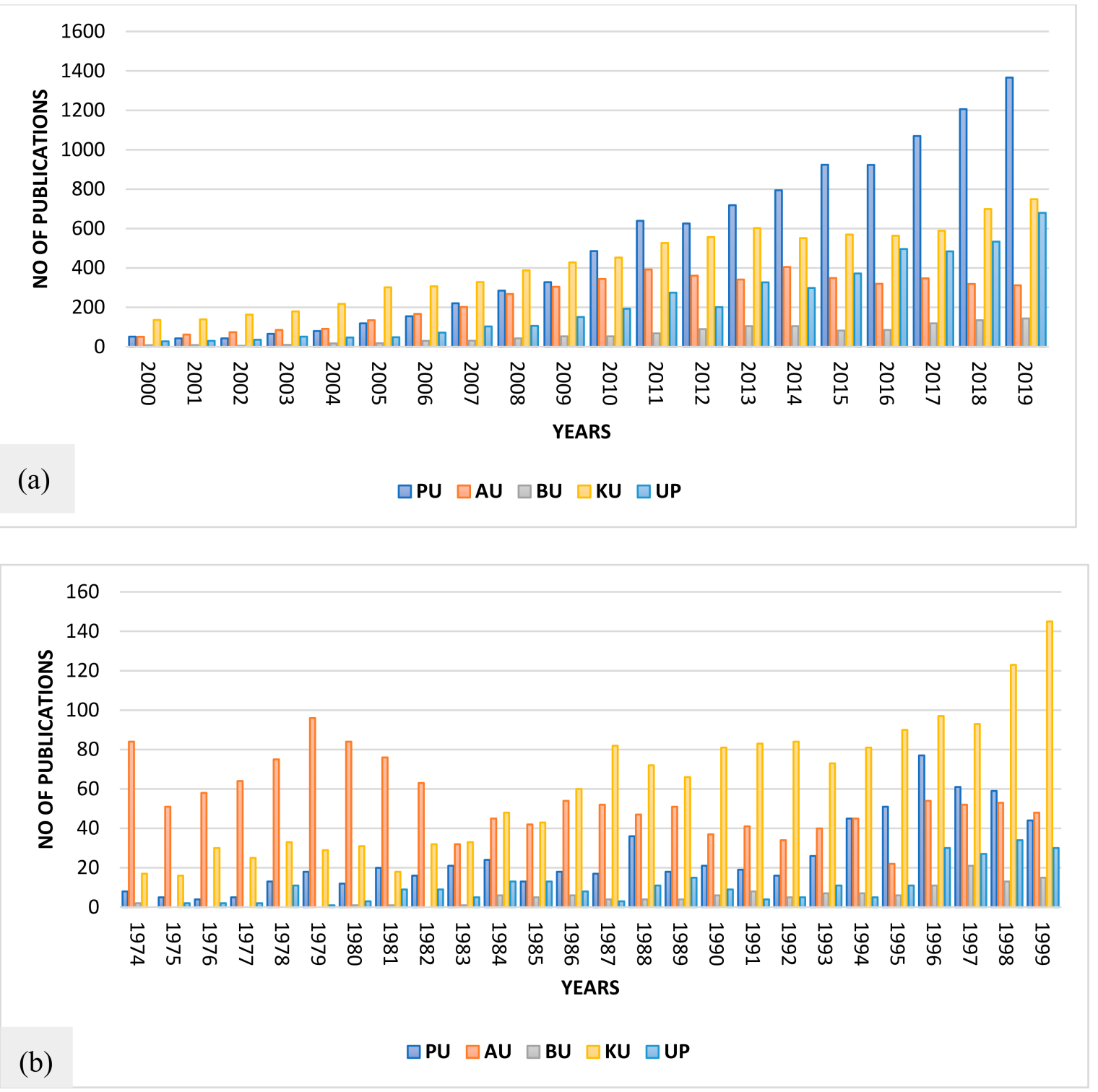

Figure 1. Shows research publications (a) from the year 2000 to 2019 (b) from the year 1974 to 1999.

Figure 2 shows that a significant share of publications is made by PU and KU that is above $59 \%$ while the least share is made from BU in this research study contributing only $3.78 \%$. PU has the highest publications share of $30.90 \%$, followed by KU with second-highest share of $28.55 \%$ in the group. AU has $23.19 \%$ publications share while UP possess $13.56 \%$ share of total publications of the studied universities.

Authors affiliated with PU and other compared universities chose to publish more than $85 \%$ of their research in subscription-based journals. Researchers in PU have more tendency to publish their research in open access journals as compared to the other studied universities. Around 22\% $(n=2427)$ of total publications' share of PU is in the open access category that is the highest in the group. Figure 3 shows preferred access types among the PU researchers to publish their research. 


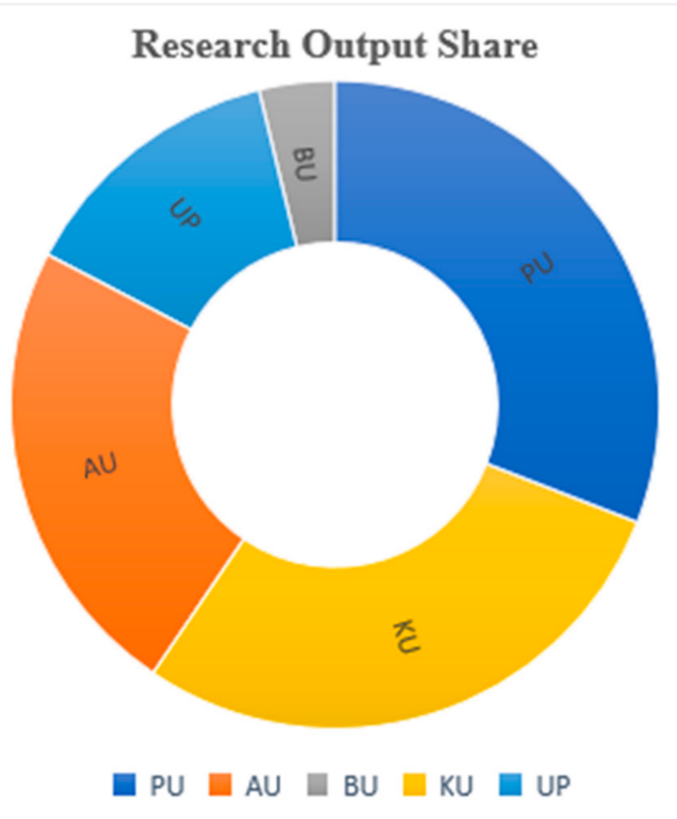

Figure 2. Share of research publications of the University of the Punjab (PU) and compared universities.

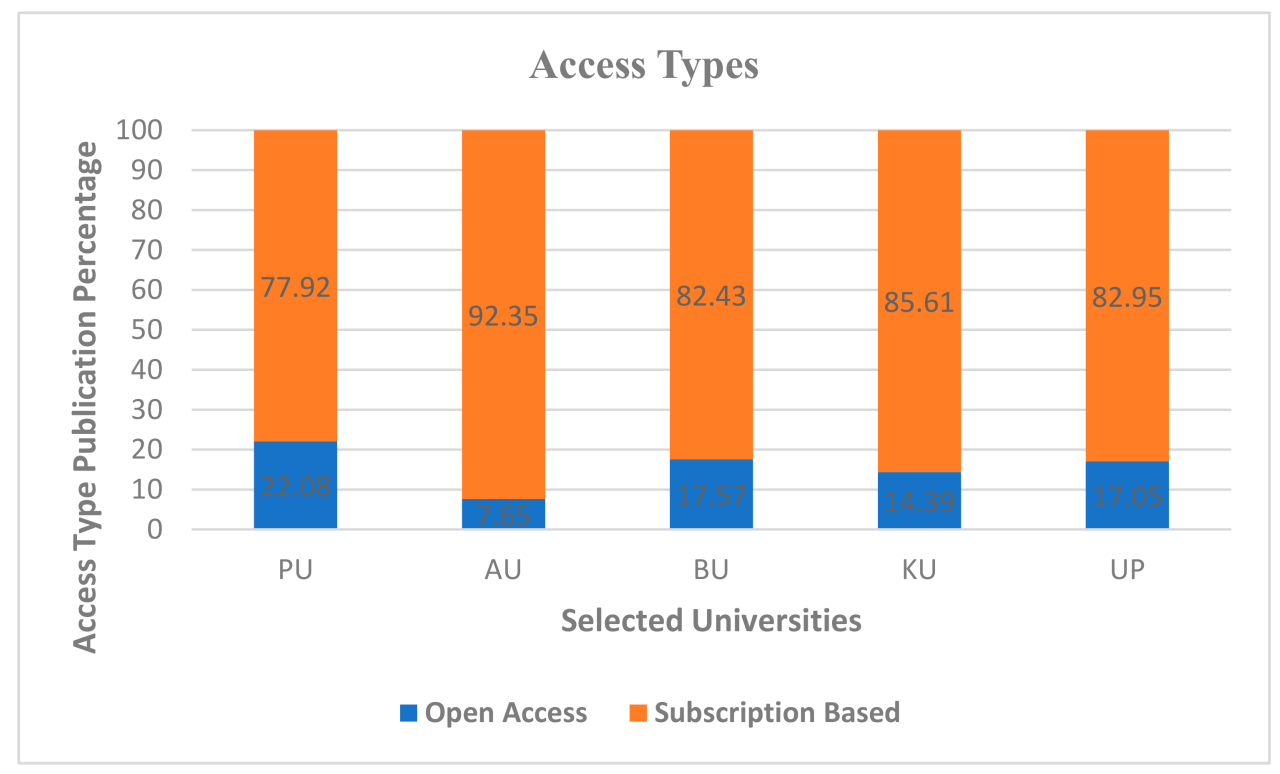

Figure 3. Shows the preferred access types of journals.

This study categorized the publications into five major categories, including Social Sciences (Business, Management, Accounting, Social Sciences, Economics, Finance, and Psychology), Engineering (all disciplines of engineering except for chemical), Medical (Pharmacology, Medicine, Medical, Veterinary sciences, Dentistry, Nursing and Neuroscience), Chemical (all types of chemistry and chemical related), and others (consisting of all other subjects other than mentioned categories). It is observed that PU's leading research areas are engineering, social sciences, and subjects categorized in the 'others' category, whereas KU's research strengths subject areas are related to medical sciences, chemistry, and chemical engineering. This study also analyzed the predefined subject categories of Scopus database and it is observed that PU is publishing more in agricultural and biological sciences followed by physics and astronomy. Chemistry, materials science, biochemistry, genetics and molecular biology, engineering, and medicine are other prominent subject areas where PU affiliated authors are 
frequently publishing their research output. Collectively, the studied universities are publishing more in chemistry compared to other subject areas. Figure 4 displays the areas of research of peer universities.

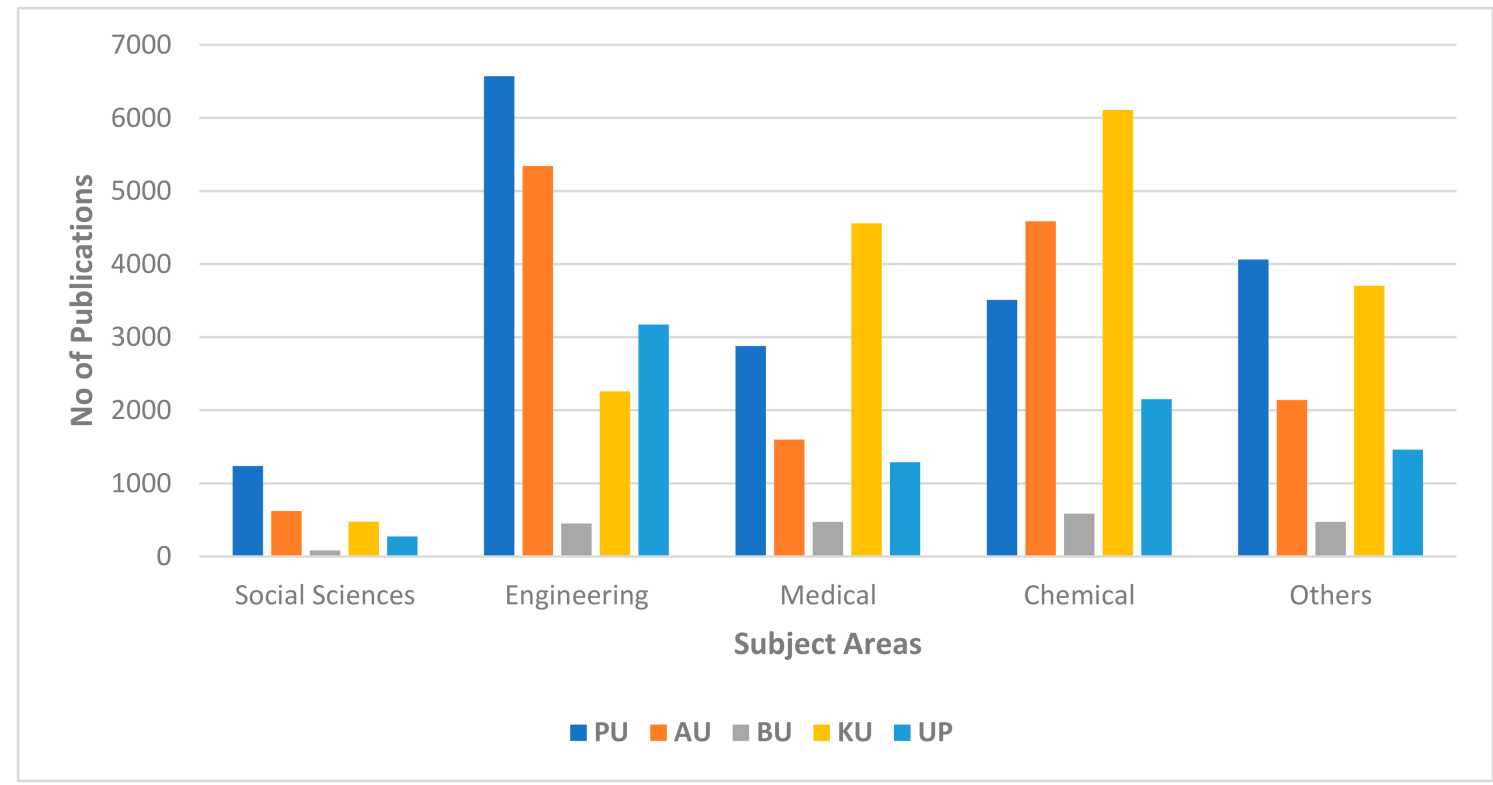

Figure 4. Research areas of PU and compared universities.

Researchers of PU and the other universities preferred to publish their research output in journal articles rather than other types, including book chapters, books, conference papers, and editorial. Figure 5 displays the distribution of preferred documents types of selected universities to publish their research.

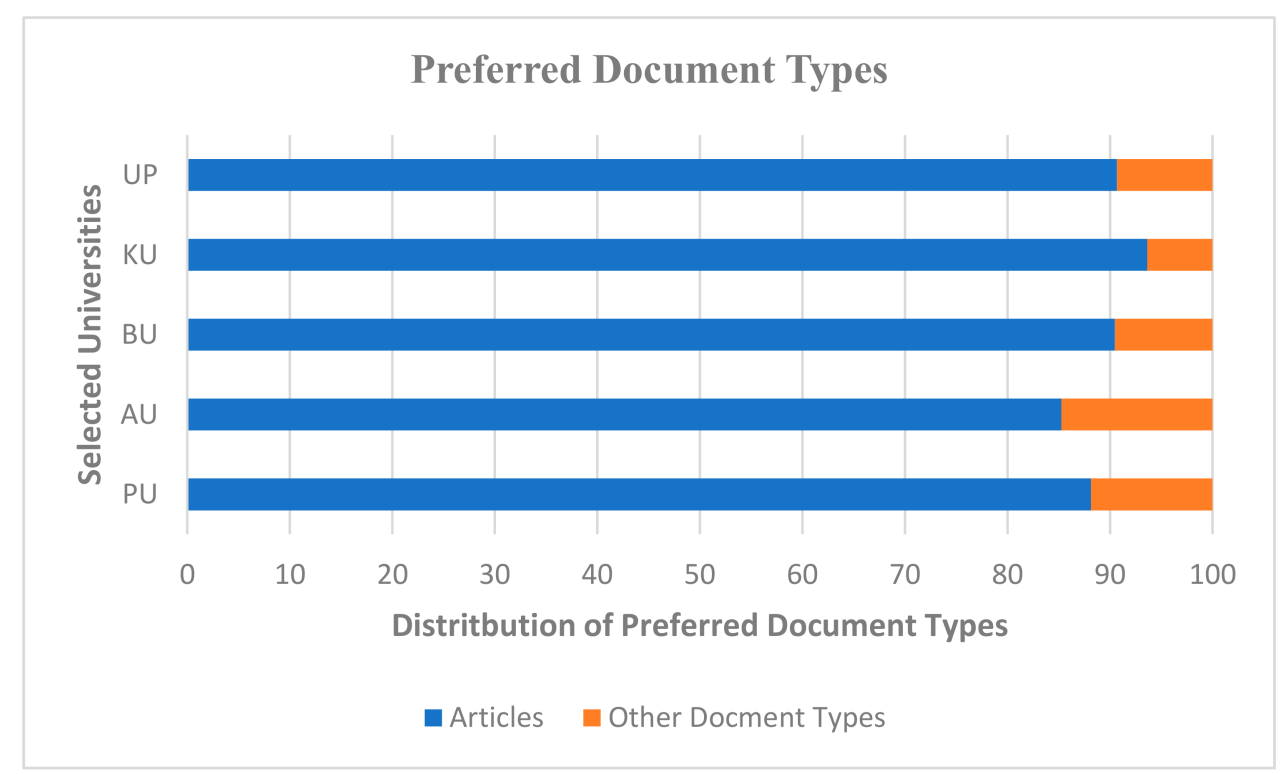

Figure 5. Preferred document types.

\section{Collaboration Patterns}

Authors of PU collaborated in 130 countries around the world. The highest number of collaborative studies are conducted with the United States authors. Neighboring China is the second most preferred country for PU authors collaborations. The United Kingdom, Germany, Italy, Netherlands, and Sweden are the top most collaborating countries, respectively, from the European region. From the Arab region, 
the researchers of PU mostly collaborated with the authors affiliated with Saudi Arabian institutions. India and Iran are the other significant neighbors for collaborations. The international collaboration trend was high in PU, as compared to other studied universities. PU made $(n=8215)$ international collaborations, the highest from all peer universities. KU, UP, AU, and BU made ( $\mathrm{n}=5032),(\mathrm{n}=2818)$, $(n=1525)$, and $(n=785)$ international collaborations, respectively. Figure 6 shows the countries of collaboration.

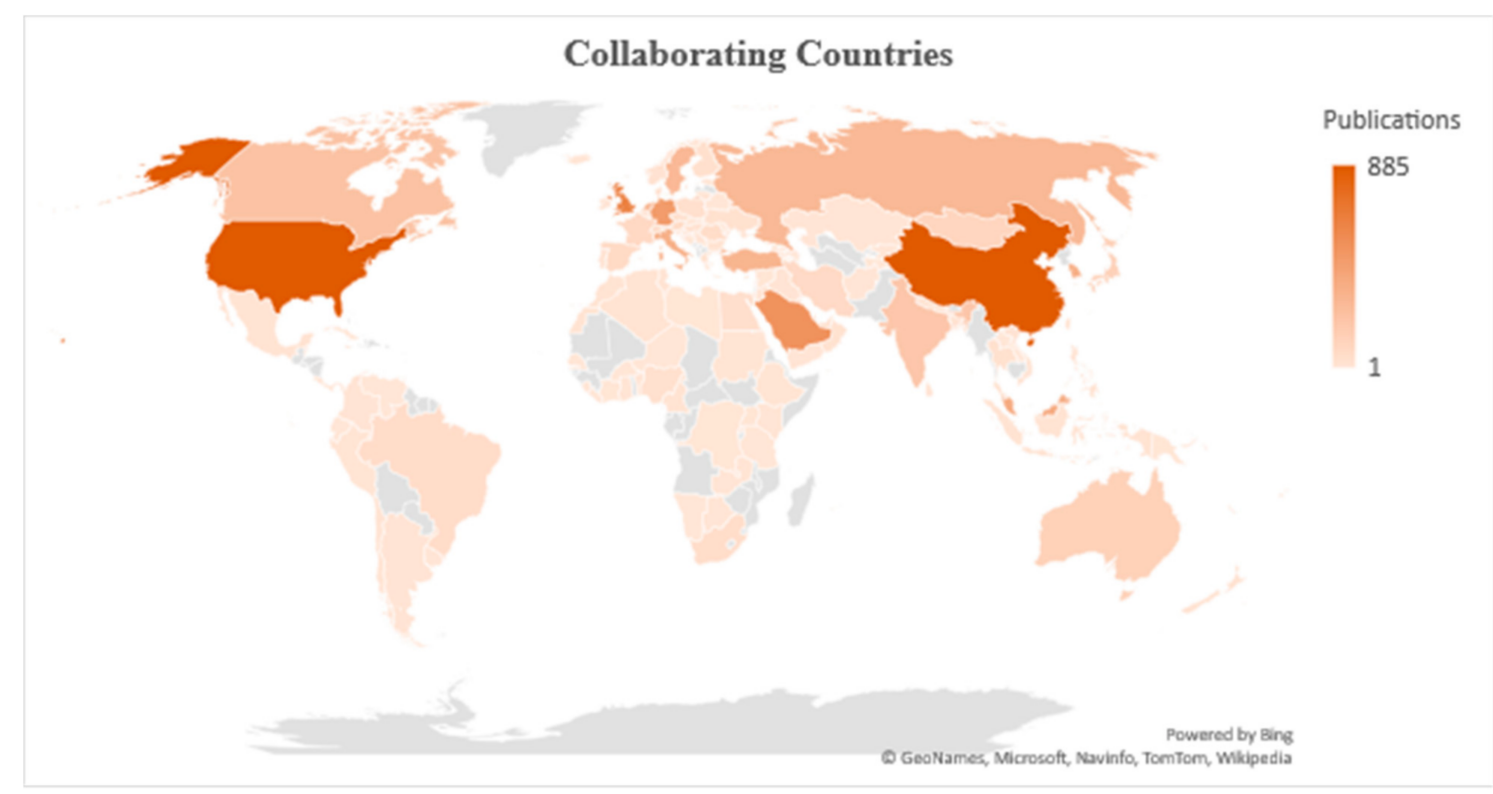

Figure 6. PU collaborations with other countries.

A detailed analysis is made to determine the institutional collaboration patterns of PU authors. Chinese institutions are dominant in international collaborations. The highest number of institutional collaborations was made with the researchers of Tsinghua University, followed by the Zhejiang University, University of Science and Technology China, Nanjing University, Peking University, and Wuhan University, respectively. University deli Study di Torino, University of Groningen, and the University of Giessen from the European region were the other universities where PU affiliated authors preferred to collaborate. Collaboration with COMSATS University was the highest domestically followed by Government College University, and the University of Sargodha, respectively. The other local institutions in the list were Islamia University, University of Lahore, Baha Uddin Zakariya University, and Lahore College for Women University. Figure 7 displays the top twenty collaborating institutes. 


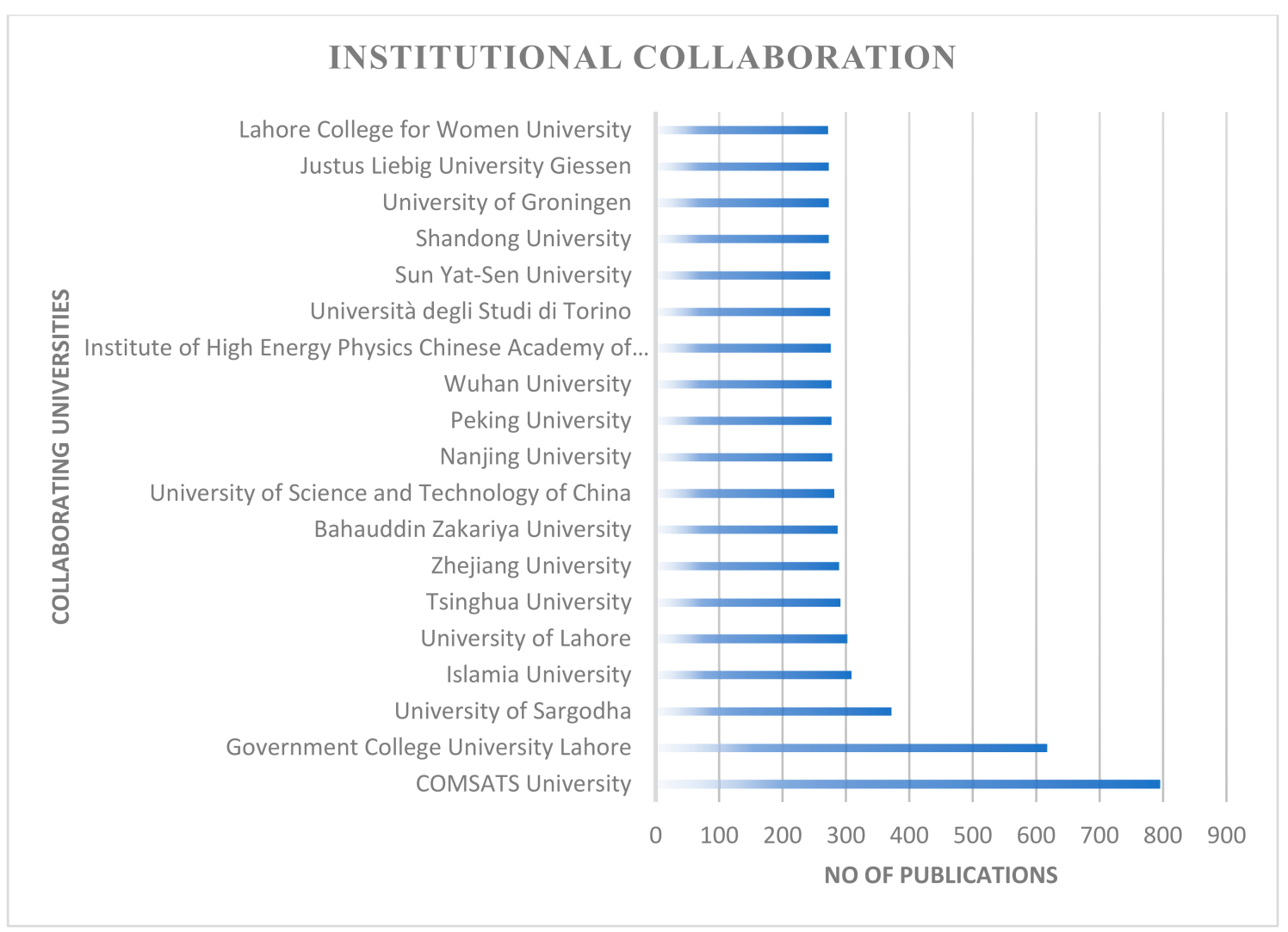

Figure 7. Institutional collaboration with local and international institutions.

\subsection{Nobel Laureates}

Internationally recognized scientific awards, notably the Nobel Prize, are one of the methods used for research estimation [49]. Nobel Prize awards are a gold standard of quality of the scientific research in the fields [50]. The University of the Punjab has produced two Nobel Laureates so far. Har Gobind Khorana was awarded the prestigious Nobel Prize in 1968 in Physiology or Medicine, while Abdus Salam was the other laureate who received the prestigious award in Physics in 1979. Other compared universities have not registered any name in the prestigious list of Nobel Laureates so far, making PU distinctive among the group with two laureates on its credit.

\subsection{Authorship Patterns}

A higher level of collaboration is observed at PU. Around 4\% $(n=491)$ of PU publications are single-authored publications while the rest of the $96 \%$ of publications are collaborative efforts. More than $30 \%(n=3308)$ of PU publications have at least six or more authors. Two-author collaboration is about $20 \%(n=2155)$ publications of PU. Three-author collaboration is about $17 \%(n=1981)$ of research studies, while four authors collaborated for $15 \%(n=1655)$ of PU publications. Five-author collaboration consists of about $13 \%(n=1463)$ of PU publications. Figure 8 shows the pattern of citations to the number of authors per publication. 


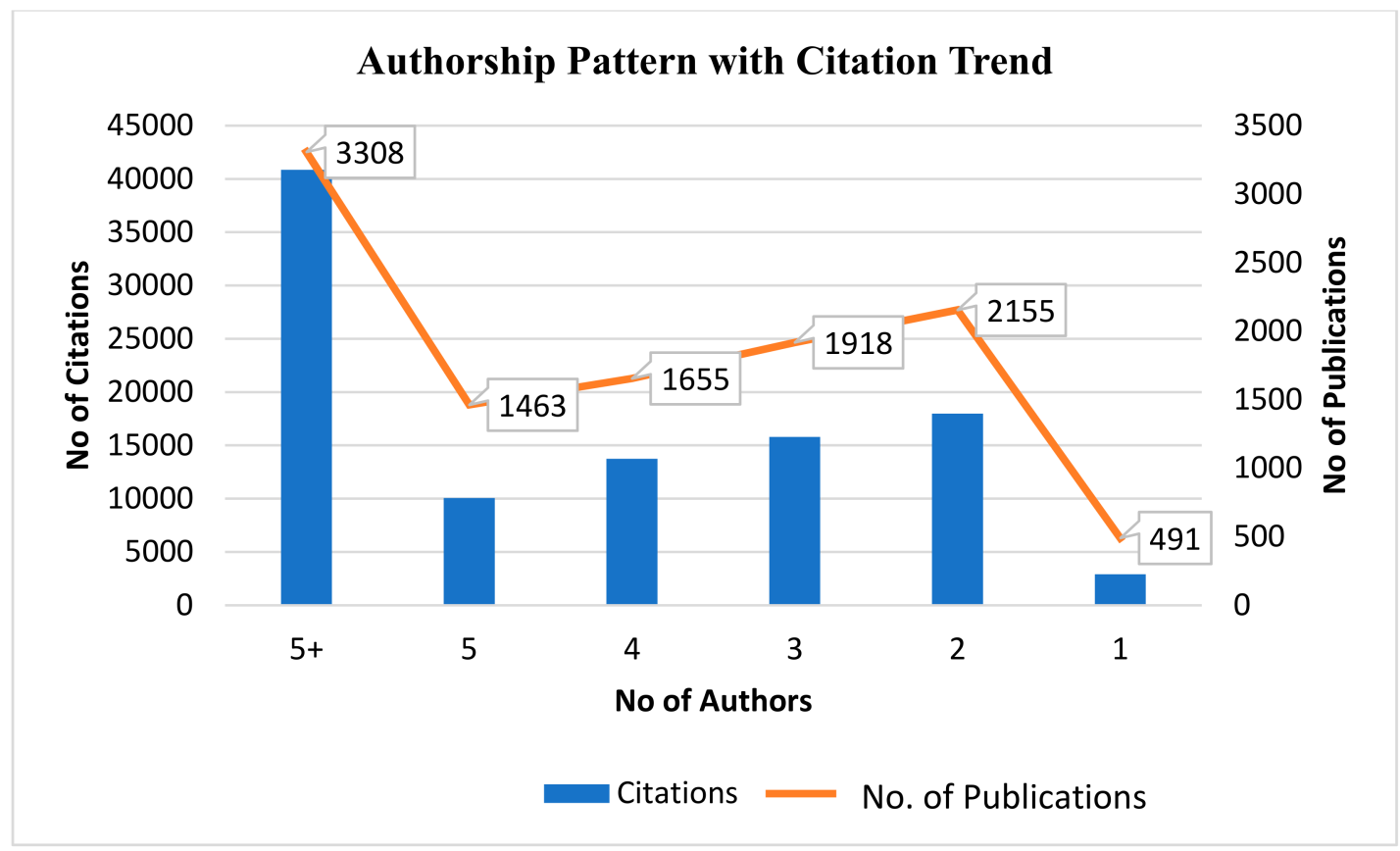

Figure 8. Number of authors per publication and citations pattern to the degree of collaboration.

\section{Impact Analysis}

This study concluded in the initial assessment that the research output of PU and other peer universities has grown over the years, mainly during the first two decades of the 21st century. However, just measuring the volume of publications is not sufficient without evaluating the impact of the research output. In this case, detailed citation analysis of PU and other universities' publications is conducted for this paper. Citations in publications by other researchers, most of the time, are an indication of quality and relevance of the work.

The data show that a significant impact of research publications that have six or more authors is observed. These publications have been cited with an average of 12 citations per publication. The single-author publications recorded the lowest average of six citations per publication. The publications with two, three, and four authors have an average of eight citations per publication. Similarly, the publications with five authors recorded seven citations per publication. To further analyze the citation dynamics of PU publications, this study analyzed the citations pattern of different access types of publications. The cited publications in open access category have a slightly higher average of citations (13 citations per publication) than the subscription-based publications (12 citations per publication). From open access documents of PU, around $74 \%$ are cited at least once or more, which shows a strong link between open-access and citation count. Table 1 provides an insight to the citations to documents of selected universities.

PU received a higher number of citations than any other peer university. The University of Karachi and University of Allahabad follow the PU, respectively. Similarly, PU also leads the peer universities in the number of cited documents followed by the University of Karachi and the University of Allahabad, respectively. The University of Karachi has the highest percentage of cited documents, while the University of Allahabad has limited citations. The highest number of citations was received by the University of the Punjab is $(n=3569)$ followed by the University of Allahabad with $(n=1575)$ citations. 
Table 1. Citations analysis of documents of PU and peer universities.

\begin{tabular}{lccccc}
\hline \multicolumn{1}{c}{ Indicators } & PU & AU & BU & UP & KU \\
\hline \multicolumn{1}{c}{ Publications } & 10,990 & 8248 & 1344 & 4823 & 10,154 \\
\hline Citations & 101,349 & 79,013 & 10,571 & 49,014 & 100,375 \\
\hline $\begin{array}{l}\text { Avg. } \\
\text { Citation/Document }\end{array}$ & 9.22 & 9.58 & 7.86 & 10.16 & 9.88 \\
\hline $\begin{array}{l}\text { Cited } \\
\text { Documents }\end{array}$ & 8256 & 6129 & 1015 & 3770 & 8189 \\
\hline $\begin{array}{l}\text { \% Cited } \\
\text { Documents }\end{array}$ & 75.12 & 74.30 & 75.52 & 78.17 & 80.65 \\
\hline $\begin{array}{l}\text { Non-Cited } \\
\text { Documents }\end{array}$ & 2734 & 2119 & 329 & 1053 & 1965 \\
\hline $\begin{array}{l}\text { \% Non-Cited } \\
\text { Documents }\end{array}$ & 24.88 & 25.70 & 24.48 & 21.83 & 19.35 \\
\hline $\begin{array}{l}\text { Max Citations } \\
\text { to a Document }\end{array}$ & 3569 & 1575 & 284 & 1085 & 379 \\
\hline
\end{tabular}

Funding Agencies

Higher Education Commission of Pakistan is the major funding source of all selected universities except AU. PU also contributed as the second most funding source for research activities and publications. Chinese and American agencies are also prominent in the list of sponsors. Figure 9 shows the main funding sponsors of research at PU.

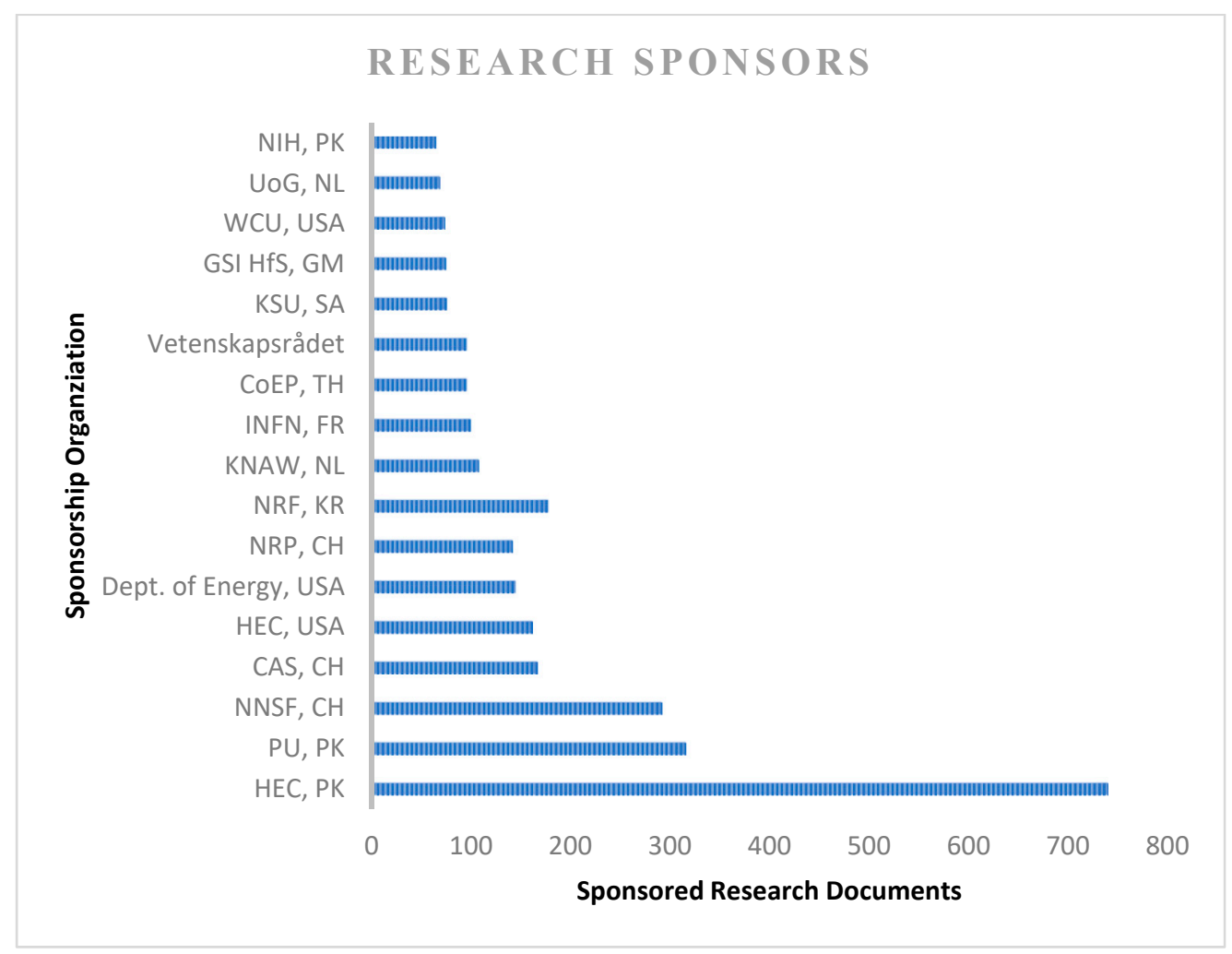

Figure 9. Funding sponsors of research at PU. 


\section{Discussion and Recommendations}

PU leads peer universities in the number of research publications and citations. The research output of PU and AU has been meagre during the last few years of the 18th century and over the 20th century. A significant increase in the publications was observed during the first two decades of the 21st century. KU has the highest percentage of cited documents. AU recorded its first research publication in 1896 while the fist research publication from PU was published in 1901. Publications associated with KU have the highest average of ten citations per document while BU recorded the lowest average of eight citations per document in the group of peer universities considered in this study. The international collaboration of PU spans to 130 countries around the world.

This study recommends the following:

- The significant growth in research publications in PU and other peer Pakistani universities is attributed to the educational reforms and the establishment of HEC at the beginning of the 21st century. The HEC's initiatives like the consortium-based subscription to online research databases through the National Digital Library Program Pakistan, Education and Research Network and National Research Programs has significantly supported the researchers and the universities to do research. This study highly recommends the continuity of such initiatives. The study also recommends the appropriate funds should be allocated to HEC for the sustainability of the research enterprise of the country.

- The findings of this study showed the direct relationship between the level of collaboration and the number of citations. Higher author collaboration leads to higher citations. Therefore, this research recommends that higher collaborative approach in the research endeavors is encouraged.

Author Contributions: Investigation: Y.J. and A.S. Methodology, S.A., Y.J. and S.H.K.; Writing-original draft, S.A. and Y.J.; Writing-review \& editing, S.A and Y.J. All authors have read and agreed to the published version of the manuscript.

Funding: This research received no external funding.

Acknowledgments: The authors are thankful to Prince Sultan University, Riyadh, Saudi Arabia, for providing the platform to conduct this study.

Conflicts of Interest: The authors declare that there is no conflict of interest.

Availability of Data and Material: The datasets used in this study is available and it can be requested from the corresponding author for future research.

\section{References}

1. Carnegie Foundation for the Advancement of Teaching. The Carnegie Classification of Institutions of Higher Education; Carnegie Foundation for the Advancement of Teaching: Menlo Park, CA, USA, 2001.

2. Rahman, T. Education in Pakistan: A survey-google books. In Pakistan on the Brink: Politics, Economics, and Society; Baxter, C., Ed.; Lexington Books: Lanham, MD, USA, 2004; p. 171.

3. Radhakrishnan, P. Indigenous Education in British India: A Profile. Contrib. Indian Sociol. 1990, $24,1-27$. [CrossRef]

4. Leitner, G.W. History of Indigenous Education in The Punjab Since Annexation and In 1882; Languages Dept., Panjab; University of Montana: Missoula, MT, USA, 1883.

5. Mayhew, A. A Comparative survey of educational aims and methods in British India and British Tropical Africa. Afr. J. Int. Afr. Inst. 1933, 6, 15. [CrossRef]

6. Basu, A. Indian Education in Parliamentary Papers; Asia Publishing House: Mumbai, India, 1952.

7. Mahmood, E.; Akhtar, M.S.; Butt, I.H. A critical review of the evolution of higher education in Pakistan. J. Educ. Res. 2015, 18, 57-75.

8. University of the Punjab-Introduction. Available online: http://pu.edu.pk/page (accessed on 7 January 2019).

9. University of the Punjab. Fact Book 2018; University of the Punjab: Lahore, Pujab, 2019.

10. Javed, S.A.; Liu, S. Predicting the research output/growth of selected countries: Application of even GM $(1,1)$ and NDGM models. Scientometrics 2018, 115, 395-413. [CrossRef] 
11. Abbot, M.; Doucouliagos, H. Research output of Australian Universities. Educ. Econ. 2004, 12, $251-265$. [CrossRef]

12. Goodall, A.H. Highly cited leaders and the performance of research Universities. Res. Policy 2009, 38, $1079-1092$. [CrossRef]

13. Coccia, M. A scientometric model for the assessment of scientific research performance within public institutes. Scientometrics 2005, 65, 307-321. [CrossRef]

14. Rodríguez-Navarro, A. Measuring research excellence: Number of Nobel prize achievements versus conventional bibliometric indicators. J. Doc. 2011, 67, 582-600. [CrossRef]

15. Garousi, V.; Mäntylä, M.V. Citations, research topics and active countries in software engineering: A bibliometrics study. Comput. Sci. Rev. 2016, 19, 56-77. [CrossRef]

16. Tang, Y.; Ren, Z.; Kong, W.; Jiang, H. Compiler testing: A systematic literature analysis. Front. Comput. Sci. 2020, 14, 1-20. [CrossRef]

17. Ramírez, M.C.; Armando, R.; Devesa, R. A Scientometric Look on Mathematics Education from Scopus Database. Math Enthus. 2019, 16, 37-46.

18. Beydoun, G.; Abedin, B.; Merigó, J.M.; Vera, M. Twenty years of information systems frontiers. Inf. Syst. Front. 2019, 21, 485-494. [CrossRef]

19. Khan, A.; Choudhury, N.; Uddin, S.; Hossain, L.; Baur, L.A. Longitudinal trends in global obesity research and collaboration: A review using bibliometric metadata. Obes. Rev. 2016, 17, 377-385. [CrossRef] [PubMed]

20. Alvarez, P.; Pulgarin, A. The rasch model. Measuring the impact of scientific journals: Analytical chemistry. J. Am. Soc. Inf. Sci. 1996, 47, 458-467. [CrossRef]

21. Chuang, K.-Y.; Olaiya, M.T.; Ho, Y.-S. Bibliometric analysis of the Polish journal of environmental studies (2000-2011). Polish J. Environ. Stud. 2012, 21, 1175-1183.

22. Donthu, N.; Kumar, S.; Pattnaik, D. Forty-five years of journal of business research: A bibliometric Analysis. J. Bus. Res. 2020, 109, 1-14. [CrossRef]

23. Ezema, I.J.; Onyancha, O.B. A bibliometric analysis of health and medical journals: Issues in medical scholarly communication in Africa. Ser. Rev. 2016, 42, 116-128. [CrossRef]

24. Xu, Z.; Zhou, W.; Baltrènaitè, E. Comprehensive bibliometric study of journal of environmental engineering and landscape management form 2007 to 2019. J. Environ. Eng. Landsc. Manag. 2019, 27, 215-227. [CrossRef]

25. Darmadji, A.; Prasojo, L.D.; Kusumaningrum, F.A.; Andriansyah, Y. Research productivity and international collaboration of top Indonesian Universities. Curr. Sci. 2018, 115, 653-658. [CrossRef]

26. Gumpenberger, C.; Sorz, J.; Wieland, M.; Gorraiz, J. Humanities and social sciences in the bibliometric spotlight-Research output analysis at the University of Vienna and considerations for increasing visibility. Res. Eval. 2016, 25, 271-278. [CrossRef]

27. García, J.A.; Rodríguez-Sánchez, R.; Fdez-Valdivia, J.; Robinson-García, N.; Torres-Salinas, D. Mapping academic institutions according to their journal publication profile: Spanish Universities as a case study. J. Am. Soc. Inf. Sci. Technol. 2012, 63, 2328-2340. [CrossRef]

28. Javed, Y.; Ahmad, S.; Khahro, S.H. Evaluating the research performance of islamabad-based higher rducation institutes. SAGE Open 2020, 10, 2158244020902085. [CrossRef]

29. Qayyum, M.; Naseer, M.M. Bio-Bibliometric Study of Dr. Khalid Mahmood's Contributions to LIS Field in Pakistan. Library Philosophy and Practice. 2013. Available online: http://hdl.handle.net/10760/18994 (accessed on 25 August 2020).

30. Kousar, M.; Mahmood, K. Dr. Syed Jalaludin Haider: A Bio-Bibliometric Study. Pakistan Journal of Information Management and Libraries. 2010. Available online: http://hdl.handle.net/10760/25605 (accessed on 25 August 2020).

31. Hou, D.; Bi, X.; Mao, Z.; Fan, Y.; Hu, X.; Li, X. Biomaterials research of china from 2013 to 2017 based on bibliometrics and visualization analysis. PeerJ Bioinform. Genom. 2019, 7, e6859. [CrossRef] [PubMed]

32. Mahbuba, D.; Rousseau, R. Scientific research in the Indian subcontinent: Selected trends and indicators 1973-2007 comparing Bangladesh, Pakistan and Sri Lanka with India, the local giant. Scientometrics 2010, 84, 403-420. [CrossRef]

33. Srivastav, A.L.; Kaur, T.; Rani, L.; Kumar, A. Scientific research production of India and China in environmental chemistry: A bibliometric assessment. Int. J. Environ. Sci. Technol. 2019, 16, 4989-4996. [CrossRef]

34. Mehar, S.M.; Chikhaoui, E.; Javed, Y.; Ahmad, S. Rohingya crises: Mapping the peer-reviewed literature. Int. J. Innov. Creat. Chang. 2019, 7, 186-199. 
35. Sweileh, W.M. Bibliometric analysis of peer-reviewed literature on Syrian refugees and displaced people (2011-2017). Confl. Health 2018, 12, 43. [CrossRef]

36. Baladi, Z.; Umedani, L.V. Pakistan journal of medical sciences: A bibliometric assessment 2001-2010. Pakistan J. Med. Sci. 2017, 33, 714-719.

37. Jan, S.U. Collaborative research in economics in Pakistan: The case of Pakistan development review from 1973 to 2009. Libr. Philos. Pract. 2017, 1, 171-181.

38. Anwar, M.A.; Saeed, H. Pakistani librarians as authors: A bibliometric study of citations in LISA-PLUS. Asian Libr. 1999, 8, 39-46. [CrossRef]

39. Naseer, M.M.; Mahmood, K. Use of Bibliometrics in LIS Research. LIBRES Libr. Inf. Sci. Res. Electron. J. 2009, $19,1$.

40. Warraich, N.F.; Ahmad, S. Pakistan journal of library and information science: A bibliometric analysis. Pakistan J. Libr. Inf. Sci. 2011, 12,1.

41. Mushtaq, A.; Abid, M.; Qureshi, M.A. Assessment of research output at higher level of educaton in Pakistan. J. Pak. Med. Assoc. 2012, 62, 628-632. [CrossRef] [PubMed]

42. Warriach, N.F.; Tahira, M. Impact of information and communication technologies on research development: A case of University of the Punjab-Pakistan. Pakistan J. Inf. Manag. Libr. 2014, 15, 47-53.

43. Warraich, N.F.; Ameen, K. Perceptions of LIS professionals regarding use of Pakistan national digital library databases. Electron. Libr. 2010, 28, 108-121. [CrossRef]

44. Baas, J.; Schotten, M.; Plume, A.; Côté, G.; Karimi, R. Scopus as a curated, high-quality bibliometric data source for academic research in quantitative science studies. Quant. Sci. Stud. 2020, 1, 377-386. [CrossRef]

45. Visser, M.; van Eck, N.J.; Waltman, L. Large-scale comparison of bibliographic data sources: Scopus, web of science, dimensions, crossref, and Microsoft academic. In Proceedings of the 17th International Conference on Scientometrics and Informetrics ISSI 2019, Rome, Italy, 2-5 September 2019.

46. Shils, E. The academic profession in India. In Elites in South Asia; Leach, E., Mukherjee, S.N., Eds.; Cambridge University Press: Cambridge, UK, 1970; pp. 172-200.

47. Howell, A. Education in British India, Prior to 1854, and in 1870-71; Office of the Superintendent of Government Printing: Calcutta, India, 1872.

48. Rahman, T. Language, Education, and Culture; Oxford University Press: Karachi, Pakistan, 1999.

49. Charlton, B.G. Measuring revolutionary science 1992-2006 using Nobel prizes, Lasker (clinical medicine) awards and Gairdner awards (NLG Metric). Med. Hypotheses 2007, 69, 1-5. [CrossRef]

50. Shelton, R.D.; Holdridge, G.M. The US-EU Race for Leadership of Science and Technology: Qualitative and Quantitative Indicators; Kluwer Academic Publishers: Dordrecht, The Netherlands, 2004; Volume 60. 